・保护论坛・

\title{
云南澄广花应该作为极小种群植物加强保护
}

\author{
任 喆1,2 陈 丽 $^{1}$ 彭 华 $^{1^{*}}$ \\ 1 (中国科学院昆明植物研究所, 昆明 650201) \\ 2 (中国科学院大学, 北京 100049)
}

\section{Orophea yunnanensis should be listed as a plant species with extremely small population}

\author{
Zhe Ren ${ }^{1,2}$, Li Chen $^{1}$, Hua Peng ${ }^{1 *}$ \\ 1 Kunming Institute of Botany, Chinese Academy of Sciences, Kunming 650201 \\ 2 University of Chinese Academy of Sciences, Beijing 100049
}

云南澄广花(Orophea yunnanensis) 是一个极度 孤立的物种, 其近缘种为产于印度的单花澄广花 (O. uniflora Hook. f. et Thoms.)(李秉滔, 1976)。根据 标本记载, 由侯宽昭先生于1940年4月1日采自云南 省江川县(今澄江县)禄充笔架山, 编号74518。自发 现近76年以来再没有在笔架山周边地区发现过, 是 一个典型的狭域物种。我们在进行云南种子植物区 划研究中, 发现它显示了该区域与热带亚洲区域久 远的地质联系。李秉滔先生和其外国同行在Flora of China (Li \& Gilbert, 2011)中记录此地的海拔是600 $\mathrm{m}$, 这一点显然有误, 山下的抚仙湖湖面的海拔就 近 $1,700 \mathrm{~m}$ 。

考虑到在周边地区一直没有发现该物种，而抚 仙湖湖滨周围又破坏很严重, 我们于2016年2月2日 到澄江县禄充笔架山对该物种进行了野外调查。笔 架山森林植被为常绿落叶阔叶混交林, 但是林冠不 整齐, 上层乔木层落叶树种较多, 而林内整体个体 数占优的是常绿成分, 以球序鹅掌柴 (Schefflera glomerulata)、窄叶石楠(Photinia stenophylla)、茶条 木(Delavaya toxocarpa)和云南木犀榄(Olea tsoongii) 等常绿灌木成分为主。由于环境条件和个体数量有 限，我们采用样线调查。在近湖滨区域的石灰岩各 类生境中, 共计得到44株个体, 20 株为大灌木, 24株 为幼树(其中 8 株为较小龄级的个体)。其生境及其开 花状况见图1。该物种为群落伴生种, 有着较健
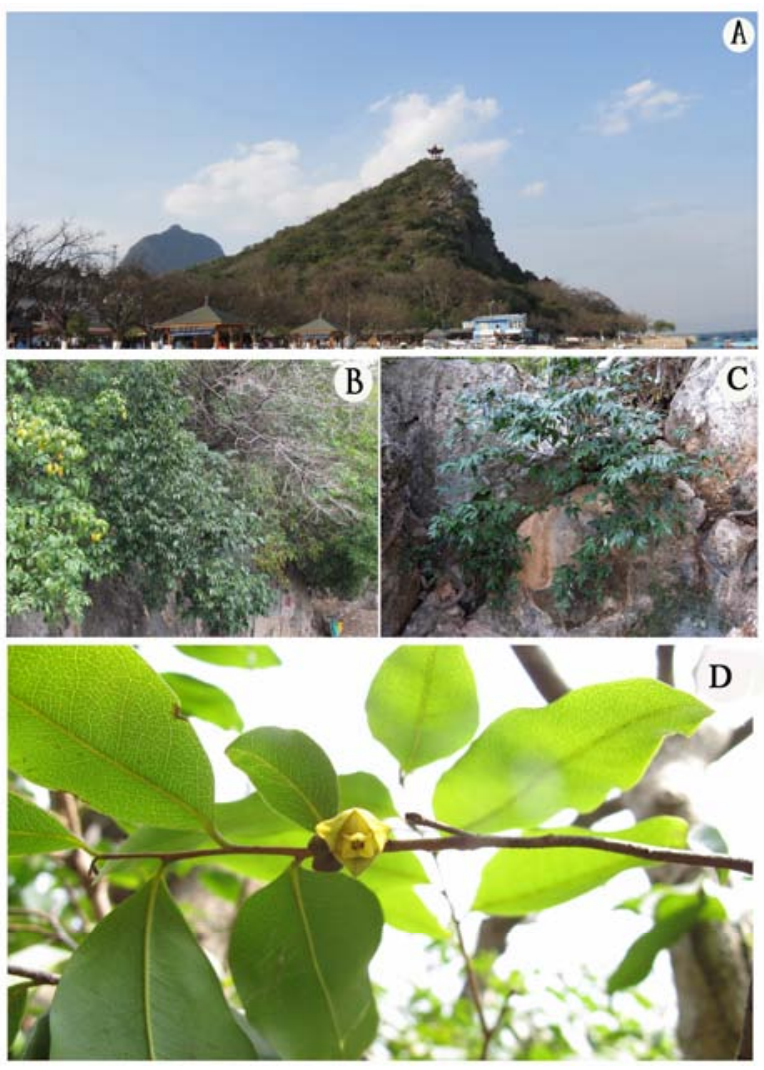

图1 云南澄广花的生境和花期照片。A: 禄充笔架山远景; B和C：云南澄广花的生境; (D)花期。

Fig. 1 Photos showing the habitat and flowering of Orophea yunnanensis. A, An overview of Bijiashan Mountain in Luchong; B and C, Habitats of O. yunnanensis; D, Flowering phase. 
表 1 在云南澄广花分布区基于样线法调查到的植物种类

Table 1 Plant species recorded with the line transect method in the distributional site of Orophea yunnanensis

\begin{tabular}{|c|c|}
\hline & 物种 Species \\
\hline \multirow[t]{2}{*}{ 乔木 Arbor } & 黄葛榕 Ficus virens \\
\hline & 构树 Broussonetia papyrifera \\
\hline \multirow[t]{23}{*}{ 灌木 Shrub } & 球序鹅掌柴 Schefflera glomerulata \\
\hline & 清香木 Pistacia weinmannifolia \\
\hline & 窄叶石楠 Photinia stenophylla \\
\hline & 茶条木 Delavaya toxocarpa \\
\hline & 驳骨丹 Buddleja asiatica \\
\hline & 云南木犀榄 Olea tsoongii \\
\hline & 匙叶栋 Quercus dolicholepis \\
\hline & 岩桑 Morus mongolica \\
\hline & 毛叶柿 Diospyros dumetorum \\
\hline & 马桑 Coriaria nepalensis \\
\hline & 樱桃 Cerasus pseudocerasus \\
\hline & 菲岛桐 Mallotus philippensis \\
\hline & 云南柳 Salix cavaleriei \\
\hline & 沙针 Osyris quadripartita \\
\hline & 红雾水葛 Pouzolzia sanguinea \\
\hline & 迎春花 Jasminum nudiflorum \\
\hline & 线毛鸡血藤 Millettia velutina \\
\hline & 粉花绣线菊 Spiraea japonica \\
\hline & 长花荛花 Wikstroemiadolichantha \\
\hline & 华西小石积 Osteomelesschwerinae \\
\hline & 鼠李 Rhamnus davurica \\
\hline & 高原雀梅藤 Sageretia gracilis \\
\hline & 枫香 Liquidambar formosana (人工栽种) \\
\hline \multirow[t]{25}{*}{ 草本 Herb } & 银针七 Leucas mollissima \\
\hline & 白草 Pennisetum flaccidum \\
\hline & 千里光 Senecio scandens \\
\hline & 毛蕓香茶菜 Isodon eriocalyx \\
\hline & 滇南素馨 Jasminum wangii \\
\hline & 土获苓 Smilax glabra \\
\hline & 扭黄茅 Heteropogon contortus \\
\hline & 拉拉藤 Galium aparine var. echinospermum \\
\hline & 短瓣花 Brachystemma calycinum \\
\hline & 千年菾 Polygonum urophyllum \\
\hline & 沿阶草 Ophiopogon bodinieri \\
\hline & 鬼针草 Bidens pilosa \\
\hline & 线形草沙蚕 Tripogon filiformis \\
\hline & 紫茎泽兰 Ageratina adenophora \\
\hline & 冷水花 Pilea notata \\
\hline & 三角叶风毛菊 Saussurea deltoidea \\
\hline & 戟叶酸模 Rumex hastatus \\
\hline & 水蔗茅 Apluda mutica \\
\hline & 香荋 Elsholtzia ciliata \\
\hline & 葪蕨 Drynaria roosii \\
\hline & 假酸浆 Nicandra physalodes \\
\hline & 刺蒴麻 Triumfetta rhomboidea \\
\hline & 桑寄生 Taxillus sutchuenensis \\
\hline & 鼠尾草 Salvia japonica \\
\hline & 菊三七 Gynura japonica \\
\hline
\end{tabular}

康的种群数量和结构。因为当年侯宽昭先生没有记 录该种的植株数, 无法对比。目前, 在该物种所处 的生境中, 紫茎泽兰(Ageratina adenophora)、鬼针 草(Bidens pilosa)和假酸浆(Nicandra physalodes)等 外来植物入侵严重, 其生存前景令人十分担忧。我 们调查中记录到的植物种类见表 1 。

李秉滔先生等在Flora of China的附注中指明 世界自然保护联盟(IUCN)把该种列为极度濒危物 种 $(\mathrm{CR})$, 可能就是考虑了这一特殊的分布格局以及 笔架山狭小的分布范围和可能的种群数量(IUCN, 2010; Li \& Gilbert, 2011)。我们调查发现，目前其种 群数量较稳定、结构合理, 有 3 个不同龄级个体存 在，但是其分布区域狭小，再加上一些建群成分如 黄葛榕(Ficus virens)、清香木(Pistacia weinmannifolia) 等盖度很大, 可能会影响其更新。而且, 我们 还发现当地在进行植树造林时引入了一些外域成 分, 如枫香 (Liquidanbar formosana), 这无疑是很不 明智的做法。

根据我们的调查结果和目前的形势(旅游热点、 环境破坏等), 亟需把这种植物作为极小种群物种 加以保护，其所在区域建议设为澄江县的保护小 区。此外, 为了更好的保护此物种, 建议探索对该 物种进行迁地保护的途经, 待深入研究后提升成具 有更强法律意义的一级保护植物。

致谢: 感谢王英、陈同江、李璐、董洪进、尹志坚、 赵飞以及玉溪市林业局保护科吴建勇等参与野外 考察和其后的整理、分析。

\section{参考文献}

International Union for Conservation of Nature (IUCN) (2010) Orophea yunnanensis is listed as Critically Endangered (CR B1ab(i,ii,v)) by the IUCN Red List of Threatened Species. http://www.iucnredlist.org. (accessed 2016-01-10)

Li PT (1976) Some notes on the Annonaceae of China. Acta Phytotaxonomica Sinica, 14(1), 96-113. (in Chinese) [李秉 滔 (1976) 中国番荔枝科的研究. 植物分类学报, 14(1), 96-113.]

Li PT, Gilbert MG (2011) Orophea Blume. In: Flora of China, Vol. 19 (eds Wu ZY, Raven PH, Hong DY), pp. 677-679. Science Press \& Missouri Botanical Garden Press, Beijing $\&$ St. Louis. 